\title{
Negative influence on human health for use and frequent i nadequado vitamin $\mathrm{C}$
}

\author{
Silva G.M1, Moraes A.R.01, Paiva E.M.C1, Silva J.P.F1, Lima L.D.M1, Neves H.J.P²
}

${ }^{1}$ In Academic Biomedicine The University Center Tabosa de Almeida ASCES-UNITA; ${ }^{2}$ Teacher of the University Center Tabosa de Almeida ASCES-UNITA

\begin{abstract}
Introduction: Vitamin $C$ or simply ascorbic acid (AA) is heat labile and water soluble vitamin. Humans and other primates are the only mammals unable to synthesize AA. The recommended dose for maintenance of vitamin $C$ saturation level in the body is about $100 \mathrm{mg}$ per day in various situations, such as infections, pregnancy and breastfeeding, and in smokers, even higher doses are required, it is in the wild under two forms: reduced or oxidized. Objective: To present the factors that negatively influence human health by inappropriate and frequent use of the vitamin population. Methodology: This is a literature review study being evaluated scientific articles published in the years 2005-2015 in journals indexed in the following SCIELO databases, Pub Med, Medlinee Science Direct. Results and Discussion: Food or vitamin $C$ supplements in excess can have some negative effects on the body. The excess of AA in the body can cause a sick person. The individual may also have vomiting and diarrhea, followed by stomach pains and moderate or severe headaches, other side effects include destruction of red blood cell hemolysis. Vitamin increases the tendency of the body to absorb iron more than the required amount. This can increase the risk of blood diseases, such as thalassemia and hemochromatosis, can accumulate in the kidneys inciting the lithiasis process, ascorbic acid can also act on the delay of surgical wounds. Conclusion: We conclude that the AA or vitamin $C$ however much it may be a benefit in some respects can bring risks if used improperly way, as pointed out above, you should always be careful and always use the evaluation of a health professional.

*Correspondence to Author:

Silva G.M

In Academic Biomedicine The Uni-

versity Center Tabosa de Almeida ASCES-UNITA

How to cite this article:

Silva G.M, Moraes A.R.O, Paiva E.M.C, Silva J.P.F, Lima L.D.M, Neves H.J.P. Negative influence on human health for use and frequent $i$ nadequado vitamin C. International Journal of Biomaterials and Nanobiotechnology. 2018, 1:4

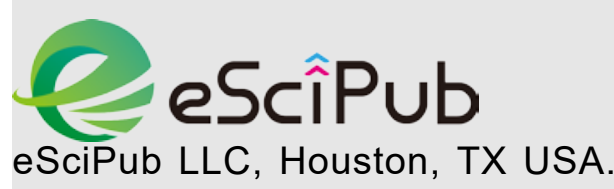

Website: http://escipub.com/
\end{abstract}

Keyword: Vitamin C; use the inadequad; Cheers. 